Document downloaded from:

http://hdl.handle.net/10251/141942

This paper must be cited as:

Lorduy, M.; Gallardo Bermell, S.; Verdú Martín, GJ. (07-2). Simulation studies on natural circulation phenomena during an SBO accident. Applied Thermal Engineering. 139:514-523. https://doi.org/10.1016/j.applthermaleng.2018.04.130

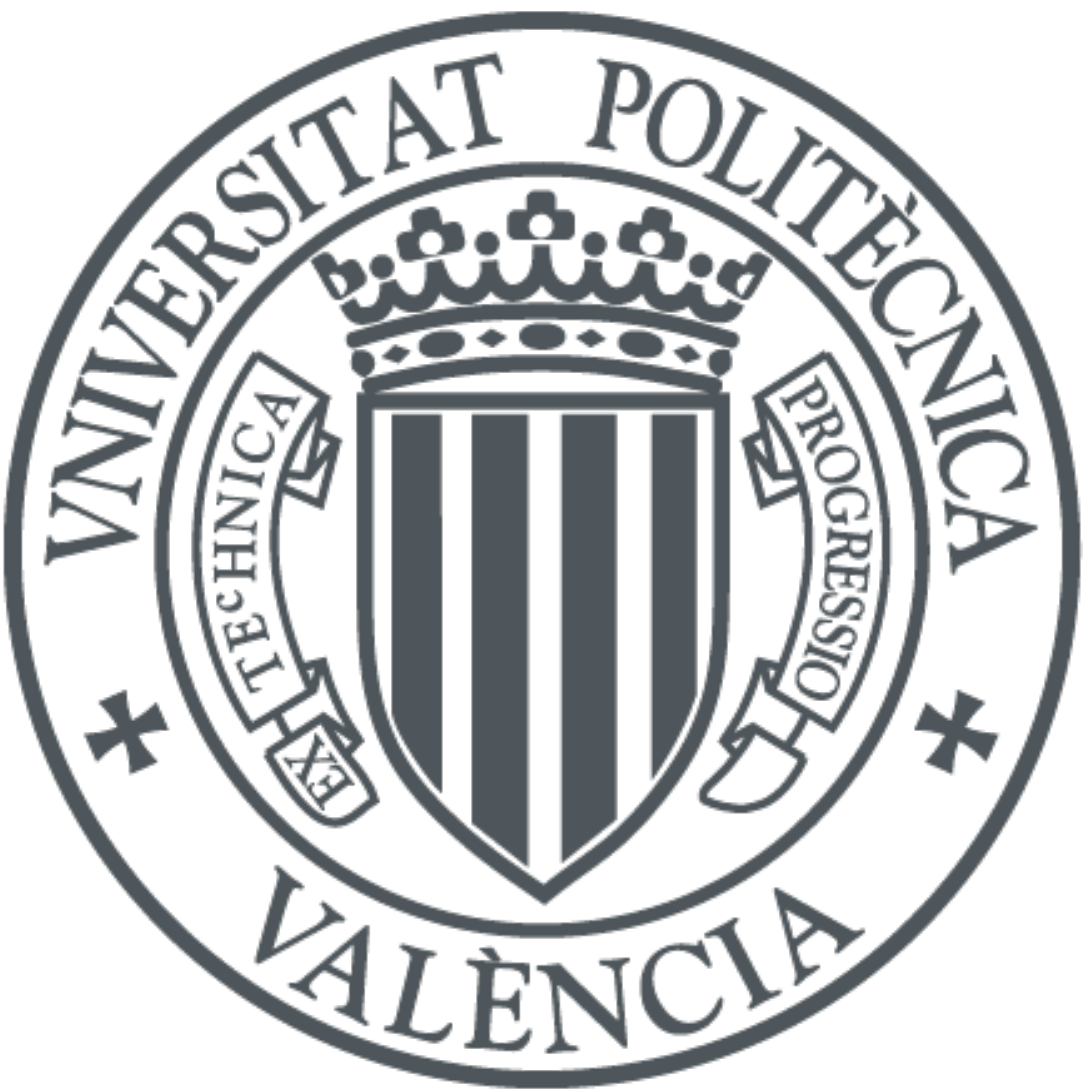

The final publication is available at

https://doi.org/10.1016/j.applthermaleng.2018.04.130

Copyright Elsevier

Additional Information 


\title{
Simulation studies on natural circulation phenomena during an SBO accident
}

\author{
María Lorduy-Alós ${ }^{\mathrm{a} *}$, Sergio Gallardo ${ }^{\mathrm{a}}$, Gumersindo Verdúa \\ anstituto Universitario de Seguridad Industrial, Radiofísica y Medioambiental (ISIRYM), Universitat \\ Politècnica de València, Camí de Vera s/n, Valencia, Spain
}

\begin{abstract}
Natural circulation flow capability for removing decay core power has been demonstrated, and several studies have focused on taking advantage of this fact. This work studies the sequence of events that occur during a station blackout accident, in which natural circulation is the dominant flow pattern in the primary system. To this end, the Test A1.1 carried out in ATLAS facility is analyzed and a TRACE5 model is developed paying special attention on the modeling of heat losses. This phenomenon is very influential in the flow capacity and this is demonstrated through the correlation $G \sim\left(Q-q_{\text {loss }}\right)^{m}$ between the net power $Q-q_{\text {loss }}$ and the mass flow $G$, that has been established from simulations under steady-state conditions. The Test A1.1 reproduction shows the TRACE5 code adequacy to investigate natural circulation phenomena, which are difficult to control in a facility. In addition, the heat loss modeling technique using constant heat transfer coefficients is substantiated.
\end{abstract}

Keywords: Natural circulation, heat losses, station blackout, ATLAS.

\section{INTRODUCTION}

Facing the impossibility of having real data of thermal-hydraulic parameters in a power plant during an accident, integral test facilities (ITF) have been built in order to reproduce their response. The main objective of these facilities is verifying safety systems and protocols, as well as validating various thermalhydraulic codes, for which programmed tests are conducted.

ATLAS (Advanced Thermal-Hydraulic Test Loop for Accident Simulation) is a laboratory destined to simulate accident effects in the APR1400 and the OPR1000, its reference reactors. Since 2007, this facility has provided data to study Design Basis Accidents (DBAs) with the aim of verifying different security features. After Fukushima accident, other Design Extension Conditions (DECs) such as station blackout or total loss of feedwater are taken into account in KAERI (Korea Atomic Energy Research Institute) research programs [1].

In the frame of OECD-ATLAS project, the authors use a TRACE5 model of ATLAS to reproduce some tests carried out at the facility. In this paper, a Station BlackOut (SBO) type accident is simulated and compared to experimental data series. This accident refers to the total loss of offsite alternating current along with the failure of all diesel generators. Given these circumstances, all active components of a power plant as pumps or isolation valves are useless, being natural circulation (NC) the dominant flow pattern during the transient.

Natural circulation phenomena entail the circulation of fluid within a loop system due to natural convection, that is, heat transport from a heat source to a heat sink because of temperature and density difference in water along the vertical pipes. Concurrently, the density difference leads to gravity forces, which drive circulation flow. From an energy approach, most of the thermal power produced by the heat source is released to the heat sink, while a small portion is converted into mechanical energy to drive the flow rate of water. As a consequence, the major inconvenient of NC systems is the weak driving force, which reduces 
the heat transfer capacity against other systems. The balance between driving and resisting forces determines the flow rate in the loop. Driving forces result from density difference between the inlet and outlet of the vessel and resisting forces are due to wall friction $\left(\Delta \mathrm{P}_{\mathrm{f}}\right)$, local friction $\left(\Delta \mathrm{P}_{\mathrm{l}}\right)$ and the fluid acceleration $\left(\Delta \mathrm{P}_{\mathrm{a}}\right)$ induced by changes in flow area or density. This balance can be expressed as:

$\Delta P_{d}=\Delta P_{f}+\Delta P_{l}+\Delta P_{a}$

where:

$\Delta P_{d}=\oint \rho g \partial z$

Being: $(\rho)$ density, (g) acceleration of gravity and (z) height.

As expressions (1) and (2) confirm, density change in the fluid and pressure loss are the most influent parameters on natural circulation flow. In spite of these circumstances, several studies have demonstrated natural circulation flow to be capable of removing decay heat in a nuclear power plant.

After an SCRAM signal and the coast down of the reactor coolant pumps, a pressurizer water reactor may be considered as a natural circulation closed loop, where the heat source and the heat sink are constituted, respectively, by the core and the steam generators. In this situation, a natural circulation flow is established and the decay heat removal is possible while the heat transfer to the secondary side is effective. Therefore, the reactor design is of crucial importance [2] to increase the driving forces at the U-tube bundles and reduce the pressure loss imposed by the geometry (annuli, pipe elbows, channels) and other devices. In addition, other important local phenomena [3] may occur during the reactor cooldown: The primary inventory contracts and causes void formation in the vessel; Presence of multiple parallel channels connecting two plenums and having different heat fluxes result in flow instability; Wangwises et al. [4] and Kim et al. [5] have studied countercurrent flow limitation (CCFL) in the hot legs because it is limiting in reflux condensation cooling mode. Moreover, advanced reactors such us Multi-Application Small Light Water Reactor (MASLWR), CAREM and SMART use natural circulation for core cooling during normal operation.

Natural circulation capabilities and the advantages of passive systems (simplicity of design, cost reduction of installation and maintenance of active component and elimination of redundant electric power supplies), have contributed to the development of passive safety systems based on natural circulation [6].

The passive residual heat removal (PRHR) system is implemented in the Westinghouse AP600 and AP1000 designs. It is a natural-circulation-driven heat exchanger attached to one hot leg and the outlet plenum of a steam generator, intended to cool the hot water in the primary system. Other reactors, like VVER-100 and SMART, have also included the PRHR among their passive safety features. This system cooling capability is assessed by means of analytical and simulation studies [7] and experiments carried out in LSTF, APEX and VISTA facilities under different accidental conditions [8][9].

A similar system can be attached to the secondary side. This concept is adopted by the previous reactors and the IV and IV+ generation Korean reactors. During the system actuation, the steam produced in the steam generators condensates and cools in a condensation heat exchanger tube located higher than the top of the steam generators. Then, gravity forces inject the water into the economizer and a NC flow is established. The secondary side decay heat removal has been proved in SPRHR and PASCAL facilities, whose purpose is the safety system assessment, and in ATLAS integral test facility. Wu et al. [10] and Kim et al. [11] have analyzed and simulated different experiments and their studies have contributed to reaching in-depth knowledge of the system performance.

Other passive systems have also been designed to remove the decay heat from innovative lead and sodium -cooled reactors [12][13]. In these cases, the reliability studies with thermal-hydraulic codes are preceded by the addition of thermal and transport properties for each liquid, and suitable correlations, to the code.

The overall plant behavior during an SBO depends on different factors, including the period until restoring the offsite power, the accident management actions taken, the emergency core cooling systems (ECCS) action or redundancy of power supplies. In this frame, ATLAS experiments have contributed to analyze natural circulation mechanisms which could cooldown the core. The aim of the analyzed test is to 
investigate the primary cool-down performance by means of delayed supply of auxiliary feedwater only to one steam generator. Starting from the experiment simulation with the thermal hydraulic code TRACE5, the influence of the heat losses modeling in the simulations is studied.

The outline of the paper is as follows. Section 2 is dedicated to materials and methods. There, some correlations under study are presented. Furthermore, the ATLAS design and its modeling are detailed, and heat losses through the wall of the pipes are justified as a NC driver. Section 3 shows simulation results of an SBO accident. Finally, Section 4 summarizes the major conclusions of this work.

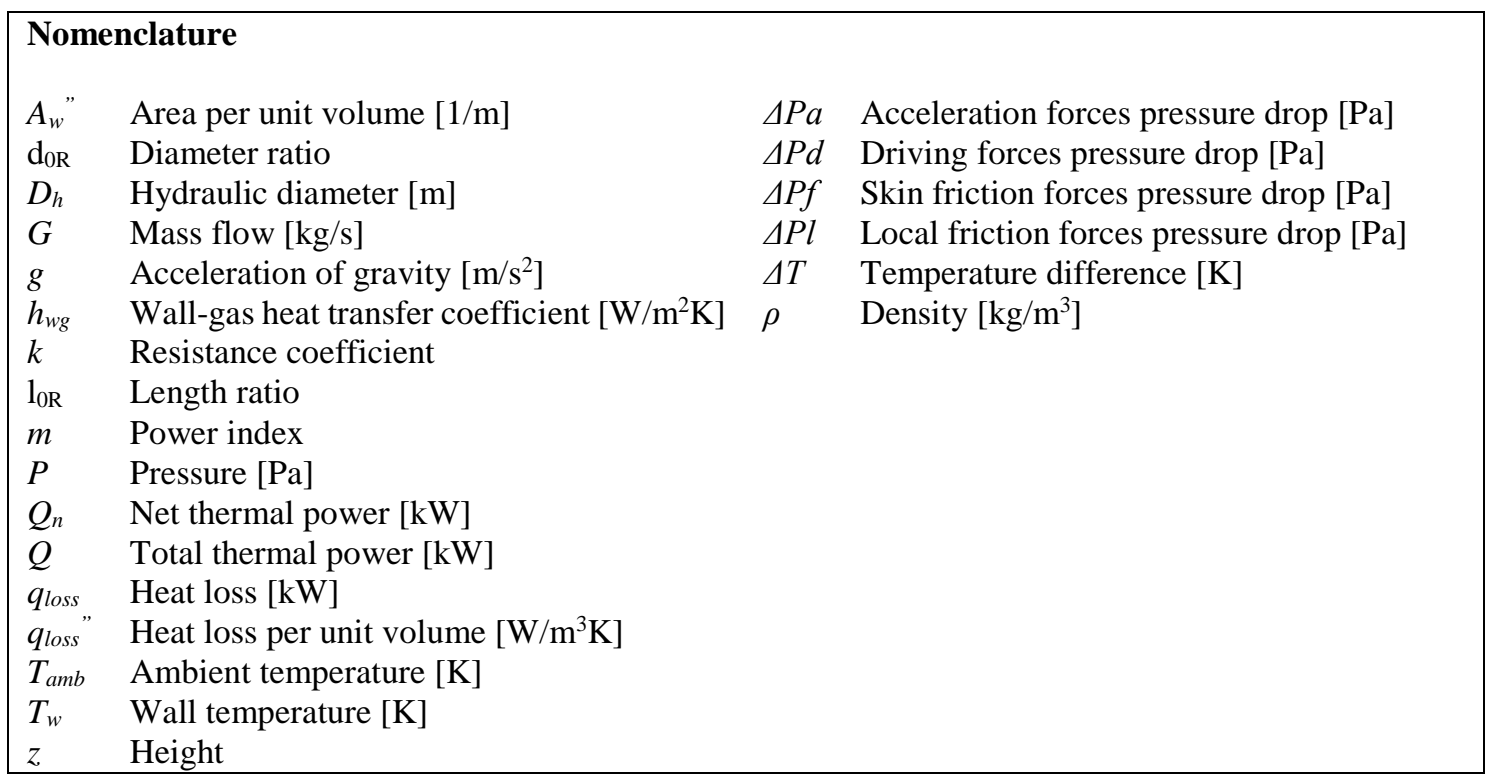

\section{MATERIALS AND METHODS}

PIRT exercises (Phenomena Identification Ranking Table) are a wide utilized methodology to identify the effects of different issues in nuclear power plants. These studies are carried out both to acquire a comprehensive knowledge about thermal-hydraulic phenomena and to plan the tests conditions that provide experimental data for studies. Among them, the PIRT destined to examine the ATLAS plant response during SBO accidents [14] points to 1-phase and 2-phase natural circulation as the major thermal-hydraulic phenomena in the primary piping system.

\subsection{Flow mass dependence of heat loss}

The relationship between natural circulation flow rate (G) and heating power (Q) may be defined in a generalist way with the power function (3). Analytical studies and experiments show a similar power index (m).

$G \sim Q^{m} \quad(3)$

Ishii and Zvirin obtained by formula derivation the power function $G \sim Q^{1 / 3}$ [15-16]. In RERI (Regional Energy Research Institute for Next Generation) experiments [17] and NPIC (Nuclear Power Institute of China) experiments [18], the dependent flow regime power index obtained is 0.4777 and 0.4053 , respectively, which was achieved by modulating the heating power. Other recent works analyze this correlation under particular conditions; Lei et al. [19] study the local pressure loss coefficient effect in this potential correlation when this parameter varies in the inlet heat source. Tan et al. [20] develop theoretical and experimental studies of single-phase natural circulation flow and heat transfer under rolling motion. 
Table 1 presents the heating power - mass flow empirical correlations achieved from these works. The experiments used to develop the correlations were conducted in test facilities with different configuration, because they have different referent reactors or scaling criteria. This fact and the test conditions involve mass flow discrepancies for a given power among the facilities. However, the power indexes are similar in all the studies to depend on the Reynolds number.

\begin{tabular}{|l|l|}
\hline \multicolumn{1}{|c|}{ Experiment } & \multicolumn{1}{c|}{ Correlation } \\
\hline Lei experiment & $\mathrm{G}=0.4274 \mathrm{Q}^{0.3674} \quad(\mathrm{k}=2.61)$ \\
\hline NPIC experiment & $\mathrm{G}=0.105 \mathrm{Q}^{0.405}$ \\
\hline RERI experiment & $\mathrm{G}=0.0352 \mathrm{Q}^{0.4777}$ \\
\hline
\end{tabular}

Table1: Mass flow - power empirical correlations

Apart from in the nuclear field, several researches have been carried out on the heating flux and NC flow capacity dependence, due to the variety of technological applications of the natural circulation loops. Namely, molten salts used in solar thermal power plants [21-22] or for mini-thermosyphon electronics cooling [23].

Experiments carried out in ITFs provide data series to help understanding thermal-hydraulic phenomena but sometimes thermal-hydraulic codes are necessary to simulate hypothetical scenarios or scenarios difficult to perform experimentally. Prolonged test simulations, as those for SBO accidents, demonstrate the importance of heat losses through the wall of the components in natural circulation. This evidence has led to analyze in this work the heat loss modeling in the A1.1 (OECD project) test. Meanwhile, it is shown the correlation between natural circulation flow rate and net heating power. To study this correlation, the power variation is considered as the heat loss effect. For that, net thermal power is estimated as the difference between the power supplied from the core and the heat loss through the loops (4).

$G \sim\left(Q-q_{\text {loss }}\right)^{m}=\left(Q_{n}\right)^{m}(4)$

\subsection{ATLAS facility}

ATLAS design is focused on its capacity to recreate the major DBAs in the APR 1400, including large break loss-of-coolant (LBLOCA), direct vessel injection (DVI) line-break accident and main steam line break accident (MSLB). In order to reproduce the loop-asymmetric phenomena and reduce the unavoidable distortion, the three-level scaling methodology of Ishii and Kataoka is applied in the scaling of the facility. This methodology ensures the preservation of the transient response of major variables, the inter-component mass and energy flows and the important local phenomena [24]. In addition, the design adopts the Reduced Height-Full Pressure criteria (scale ratios 1/2 height, 1/144 area and 1/288 volume), thus pressure and temperature are the same as those of the reference plant. As a result of the Reduced Height criterion, time scaling ratio is $1 / \sqrt{2}$ and the duration of the experiments is $\sqrt{2}$ faster than expected duration in the APR1400. Despite this scaling disadvantage, $1 / 2$-height criterion allows the use of an integrated annular downcomer around the vessel, essential in a realistic simulation of multi-dimensional phenomena [25]. Table 2 summarizes major scaling ratios of ATLAS [24].

\begin{tabular}{|c|c|c|}
\hline Parameters & Scaling ratio & ATLAS design \\
\hline Length & $l_{0 R}$ & $1 / 2$ \\
\hline Diameter & $d_{0 R}$ & $1 / 12$ \\
\hline Area & $d_{0 R}^{2}$ & $1 / 144$ \\
\hline Volume & $d_{0 R}^{2} l_{0 R}$ & $1 / 288$ \\
\hline Core temp & $\Delta T$ & 1 \\
\hline Pressure & $p$ & 1 \\
\hline Velocity & $l_{0 R}^{1 / 2}$ & $1 / \sqrt{2}$ \\
\hline Time & $l_{0 R}^{1 / 2}$ & $1 / \sqrt{2}$ \\
\hline Flow rate & $l_{0 R}^{1 / 2}$ & $1 / 203.6$ \\
\hline Pressure drop & $l_{0 R}$ & $1 / 2$ \\
\hline
\end{tabular}

Table 2: ATLAS scaling ratios. 
ATLAS facility incorporates most of the features of the APR1400 in the primary system, secondary system, safety system, break system and an auxiliary system. The primary system is composed of a vessel (RPV), two hot legs, four intermediate legs, four cold legs, a pressurizer, four pumps and two steam generator tube bundles. The RPV is one of the most important differentiating characteristic of ATLAS with respect to other test facilities since the annular downcomer improves the simulation of local phenomena [24]. The power supplied to the water is transferred through the core to preserve the distributions of temperatures, pressure drop and volumes, by means of 396 electrically heated rods with the capability to simulate $10 \%$ of the scaled power. The secondary system is simplified into two steam generators, one main steam line and one condensation and refrigeration loop, so that the produced steam is condensed and introduced in the steam generators. On account of the facility objectives, most of the safety features of the reference plant are available to perform the accidental scenarios. Among others, a pilot-operated safety relief valve (POSRV) placed on the top of the pressurizer and two trains with three steam safety valves (MSSV) prevent the primary and the secondary system, respectively, from overpressure and allow the safety injection pumps (SIP) injection to avoid the core uncover.

In addition, ATLAS is highly instrumented, allowing the measurement of thermal-hydraulic conditions (differential and static pressure, temperature, flow rate, water level, etc.) along the facility. In any case, measured data should be analyzed in accordance with the uncertainty level of each instrument [26].

\subsection{TRACE5 model}

In the frame of OECD-ATLAS project, a TRACE5 model of ATLAS provided by the U.S. Nuclear Regulatory Commission (USNRC) is modified to study natural circulation phenomena during a prolonged station blackout transient.

TRACE5 code is developed by USNRC and joints RELAP5, RAMONA, TRAC-B and TRAC-P code capabilities. It is a Best-Estimate code designed to simulate accidental scenarios in light water reactors (LWR) and their scaled test facilities. To that end, an input file that describes the model geometry with components and its nodalization (pipes, valves, pumps...) is created. Besides, it is necessary to specify options related to heat transfer, friction coefficients and the initial conditions of the programmed simulation. From these data, the code calculates the flux conditions and heat transfer along all the components of the model, and gives as a result thermal-hydraulic variables (liquid and gas velocity, liquid and gas temperature, void fraction, gas and non-condensable gas pressure, heat structures temperature, etc.)

TRACE solves a differential equation system based on Navier-Stokes equations for single phase flow. The mathematical model is composed of six continuity equations for mass, momentum and energy (3eqs. per flux phase) to model the behavior of two-phase flow. Furthermore, some equations are required to solve the system. They are usually empirical type and may be classified as equations of state, which relate a fluid state variable with two thermodynamic variables, and outline equations, to model friction and heat transfer between liquid and gas phases and each phase with the pipe walls.

The facility is modeled using 78 hydraulic components (5 BREAK, 3 FILL, 53 PIPE, 4 PUMP, 1 PRIZER, 2 SEPARATOR, 2 TEE, 7 VALVE and 1 VESSEL) [27], as Figure 1 depicts.

The last component allows simulating the multidimensional behavior of water in the vessel, and it includes an annular downcomer, lower plenum, core, upper plenum and upper head. It consists of 760 volumes divided into 19 axial levels, 8 azimuthal sectors and 5 radial rings, which represent 3 radial rings for the rods position, 1 radial ring for the reflector zone and the outermost ring for the downcomer. This radial distribution implies a non-heated volume of water around the downcomer, while power is concentrated in the central area. The 3-D vessel also permits modeling guide tubes along the core and through the upper plenum, which are located in their real position inside the vessel. The proper modeling of the position of the tubes leads to obtain a more homogeneous temperature at their ends. 
PRIMARY SYSTEM

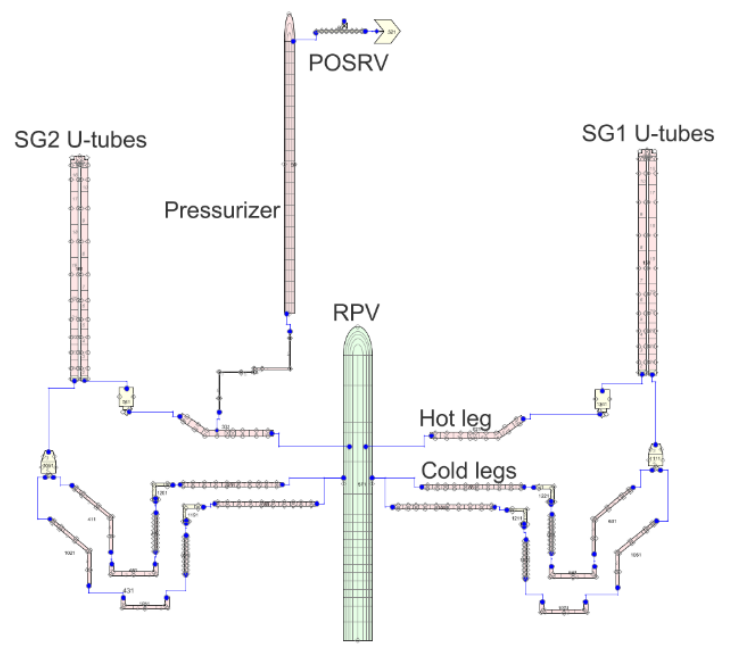

STEAM GENERATOR

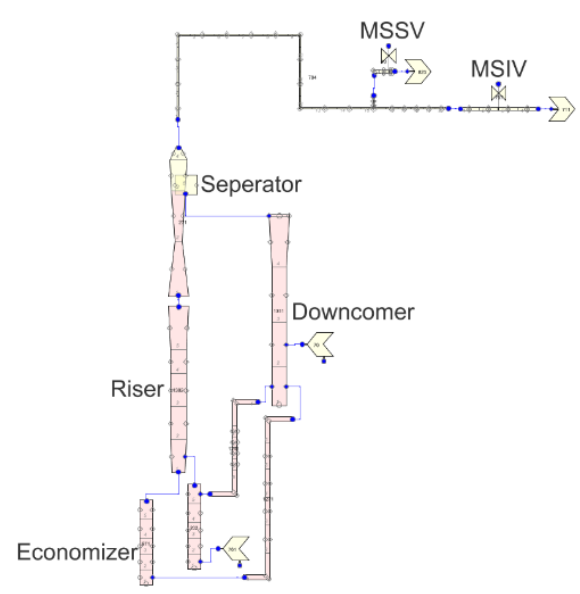

Figure 1: Model nodalization.

The U-tube bundles comprise 176 tubes distributed among 11 different levels. The model of each U-tube bundle must preserve inlet and outlet temperature, pressure drop and overall heat transfer during single or two-phase flow to simulate properly thermal-hydraulic phenomena such as countercurrent flow, condensation or flooding velocity (Wallis number). To this end, the U-tube bundles are modeled by a pipe which capacity and the flow area are equal to those of the 176 tubes and the hydraulic diameter is the same as that of each of the tubes. The total height is conditioned by the riser dimensions and it is an intermediate height between the highest and lowest level of the U-tube bundle.

Regarding the secondary side, the steam generators are the major component due to their importance and complexity. Since these devices consist of complicated internal structures, the risers and the economizers can be modeled characterizing them by a hydraulic diameter and flow area [28].

Accidents reproduction with TRACE code also requires some thermal processes modeling. To this end, POWER components act as heat sources to simulate the power supplied by the heater rods in the core and the proportional heater in the pressurizer. Moreover, heat structure (HTSTR) components model the heat transfer through the U-tubes, and in the vessel and the steam generators between their inner zone (core and riser) and their respective annular downcomers.

TRACE5 code computes heat losses per unit volume $\left(q_{\text {loss }}^{\prime \prime}\right)$ [29] from the pipes to the environment from equation (5) and the transfer surface per unit volume $\left(A_{w}^{\prime \prime}\right)$ is given by equation (6).

$q_{\text {loss }}^{\prime \prime}=h_{w g}\left(T_{w}-T_{a m b}\right) A_{w}^{\prime \prime}$

$A_{w}^{\prime \prime}=\frac{4}{D_{h}}$

Being $\left(h_{w g}\right)$ the wall-gas heat transfer coefficient and $\left(\mathrm{T}_{\mathrm{w}}\right)$ and $\left(\mathrm{T}_{\mathrm{amb}}\right)$ the wall and ambient temperatures, respectively.

In order to evaluate this process, the most widely used technique by the modelers consists in choosing constant heat transfer coefficients for each facility component. The application of this methodology is adequate if experimental data on heat losses from separate effect tests are available. However, it is important 
to highlight that the heat transfer coefficients depend on the flux properties and during a nuclear accident, these properties may change abruptly.

ATLAS model also considers pressure drops along the loops. Pressure drop due to local friction is modeled with k-factors along the pipes and the core. They have been estimated from the simulation of several experiments with isolated models. The code evaluates wall friction from the wall roughness of each pipe. The value set is $5 \mathrm{E}-5 \mathrm{~m}$, for being a common value in stainless steel pipes.

\subsection{Heat loss effect in a natural circulation loop}

Test facilities usually have a large coolant contact surface area to coolant volume ratio [30]. This results in metal heating and heat loss effects during prolonged transients. In particular, the heat loss has been a remarkable aspect of the analysis of experiments carried out in ATLAS. In the light of the foregoing, KAERI researchers conducted three separate tests [24] in order to characterize the thermal process and developed the empirical equations (7), (8) and (9) to estimate heat losses as a function of the fluid temperature. The tests allowed evaluating the heat losses in the primary system including the vessel and legs, in the secondary system and in the pressurizer.

$q_{\text {loss }, \text { prim }}=0.091 \cdot\left(T_{w}-T_{\text {atm }}\right)^{\frac{5}{4}}(7)$
$q_{\text {loss }, \text { sec }}=0.00077 \cdot\left(T_{w}-T_{\text {atm }}\right)^{1.8843}$ (8)
$q_{\text {loss }, \text { pressurizer }}=0.00227 \cdot\left(T_{w}-T_{\text {atm }}\right)^{1.53}$

In this work, a heat loss model and the correlation developed between the net thermal power and the natural circulation flow are based on the Test A1.1 initial conditions. Under these steady-state conditions, the boundary conditions on the secondary system (pressure, temperature and inventory) are imposed. The liquid level and temperature conditions set in the steam generators imply that heat losses in the secondary system do not affect the heat transfer through the U-tubes. Consequently, secondary heat losses only modify the efficiency of the steam production and do not influence the natural circulation primary flow. Moreover, due to the pressurizer island position, its heat losses do not have effects on this parameter. From these premises, only the heat losses on the primary system are analyzed.

On the other hand, some characteristics of the facility and its configuration allow accepting the modeling technique using only one constant heat transfer coefficient (HTC) in the primary system. First, most metallic structures in ATLAS are made of the same type of stainless steel (316SS) to minimize corrosion problems [31]. Table 3 shows some 316SS properties depending on the temperature [31]. Second, the single phase flow pattern along the primary loops remains unchanged independently on the location both in normal operation and natural circulation conditions.

\begin{tabular}{|c|c|c|c|}
\hline Temperature $[\mathrm{K}]$ & Density $\left[\mathrm{kg} / \mathrm{m}^{3}\right]$ & Specific heat $[\mathrm{J} / \mathrm{kgK}]$ & $\begin{array}{c}\text { Thermal conductivity } \\
{[\mathrm{W} / \mathrm{mK}]}\end{array}$ \\
\hline 300 & 8238 & 468 & 13.4 \\
\hline 600 & 8238 & 550 & 18.3 \\
\hline 900 & 8238 & 589 & 22.7 \\
\hline
\end{tabular}

Table 3: $316 S S$ properties

The estimation of a heat transfer coefficient to model the heat losses from the primary system to the environment is carried out using a series of steady-state simulations. For this purpose, the HTC set on the steam generators (secondary system) and on the pressurizer remains constant and the heat transfer coefficient set along the hot and cold legs and the vessel is varied between 0 and $25 \mathrm{~W} / \mathrm{m}^{2} \mathrm{~K}$ [32]. As shown in Figure 2, the simulations results reproduce a linear correlation between the HTC and the heat losses calculated by the code. This correlation provides a HTC to be used by TRACE5 code to simulate the KAERI 
empirical heat losses. Equation (7) estimates about $100 \mathrm{~kW}$ of heat loss rate in the primary system when ATLAS operates at 1.64 MW and 16 MPa (Test A1.1 initial conditions). Starting from the heat losses calculated by the empirical equation, the HTC-Heat loss correlation provides an HTC of $18 \mathrm{~W} / \mathrm{m}^{2} \mathrm{~K}$, which will be set in the model used in Section3.

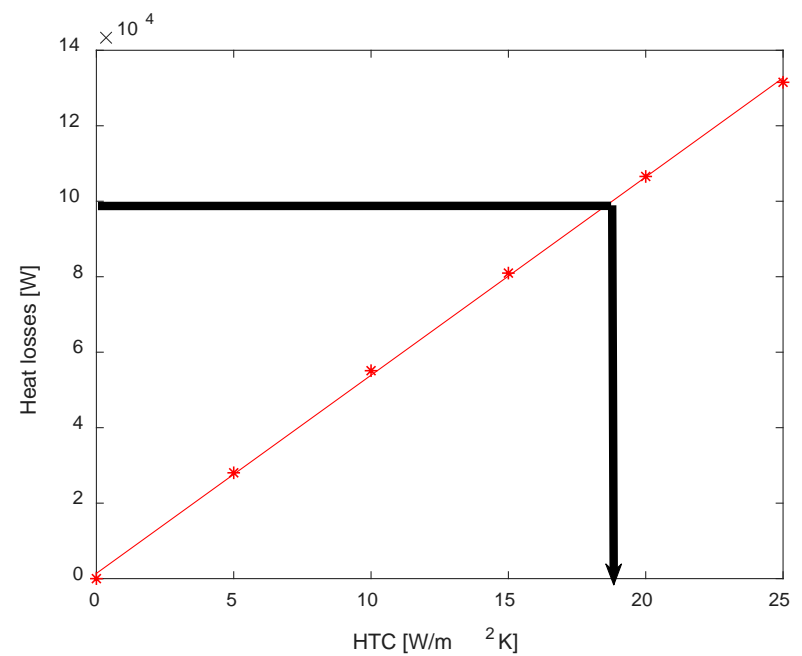

Figure 2: Heat transfer coefficient - heat loss.

As expected, heat losses reduce the net power and, therefore, the thermodynamics properties change. As Figure 3 shows, an increase in the HTC causes an overall increase in the loop density, which is measured at the vessel inlet. This phenomenon occurs regardless of the core power if the tests conditions are modified to be $60 \%, 80 \%$ and $120 \%$ of the power supplied in the test A1.1.

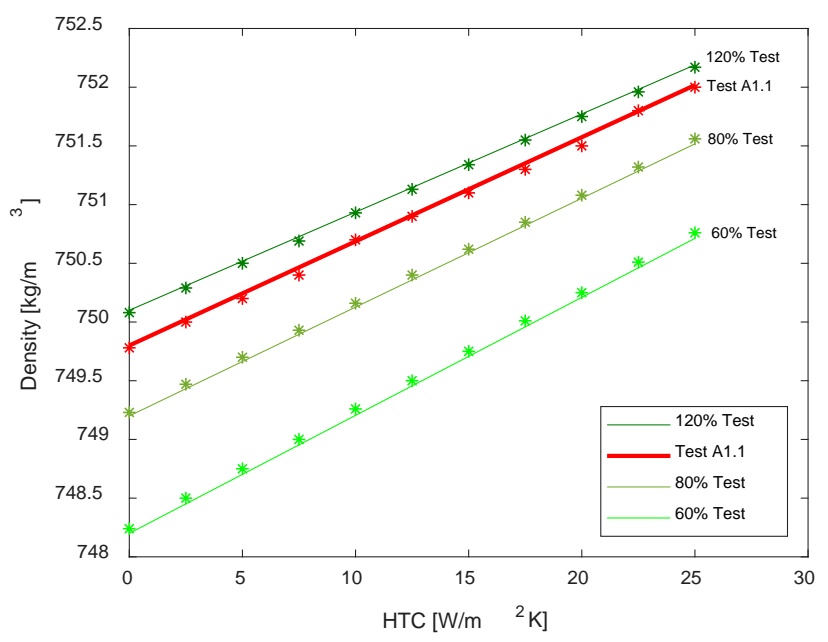

Figure 3: Heat transfer coefficient - density correlation.

TRACE5 simulations also provide the heat losses through the pipe walls dependent on the heat transfer coefficient set, and the mass flow rate that is established in the loops in each case. From these data, the correlation $\mathrm{G} \sim\left(\mathrm{Q}-\mathrm{q}_{\text {loss }}\right)^{\mathrm{m}}$ between the net power (half the core power minus heat losses) and the mass flow rate in a loop is developed. The approach to fitting these parameters with a power function results in a power index (m) of 0.3518 as the characteristic parameter in the correlation, if the core power of $1.64 \mathrm{MW}$ in the test A1.1 is considered. In Figure 4, the correlation under the KAERI experiment conditions is drawn with the results obtained by the same methodology and modifying the test specifications. To do that, the power supplied by the core is also controlled to be $60 \%, 80 \%$ and $120 \%$ the power supplied in the test A1.1, 
in order to verify the adequacy of the estimated parameters in a broader range of power. According to the simulation results, the correlation is valid for the entire range of power.

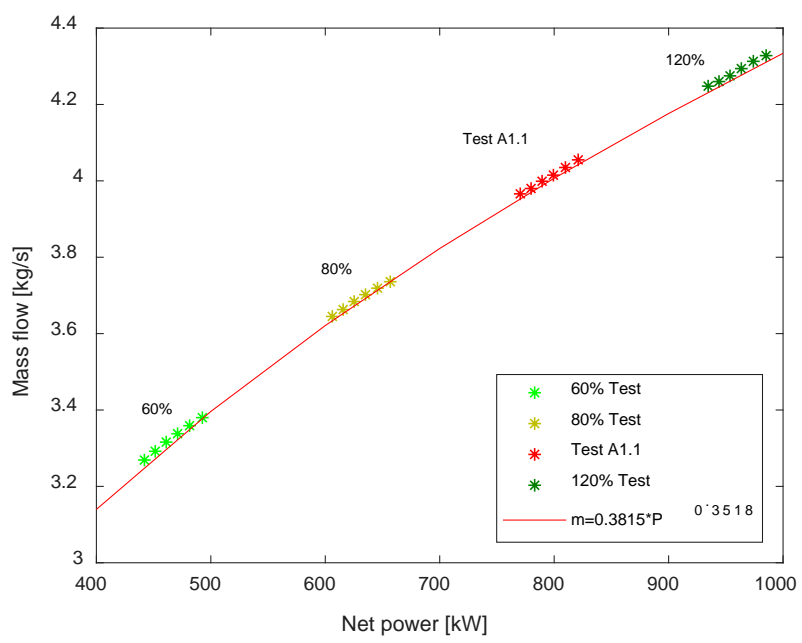

Figure 4: Net power - mass flow correlation.

In Figure 4, the methodology to establish a net power - mass flow correlation, from a fixed power minus the heat losses, can be accepted. The power function fits properly with simulation data (R-square equal to 0.998) and the power index is coherent with the analytical ones found in the literature [17-19].And as the figure shows, the correlation is valid for a wide range of power. Besides, it is noticeable the similarity of this correlation with the correlations established empirically in other test facilities (Section 2.1).

Concerning a facility model, the graphic determination of heat transfer coefficients is the starting point for an accurate adjustment of heat losses. The net thermal power determines the water thermodynamics properties and, consequently, the natural circulation capacity of the loop. For this reason, an experienced modeler should consider a slight increase or decrease of this HTC. The timing of occurrence of the events during a transient also depends on the heat losses at other locations (such as the secondary system or the pressurizer). For this reason, in order to model the facility, an analysis of the coefficients must be carried out for all the components. Once the coefficients are set, they can be maintained for the reproduction of different experiments in that model.

\subsection{Test A1.1 procedure}

Test A1.1 of the OECD-ATLAS project was carried out with the aim of studying high-pressure asymmetric single- and two-phase natural circulation flow characteristics and the effects of cooling during a SBO accident. This accident refers to the total loss of offsite alternating current along with the failure of all diesel generators, and the importance of their consequences comes from the fact that many systems in a nuclear power plant require AC power to perform their safety functions.

The experiment consists in the reproduction of a station blackout scenario with asymmetric and delayed feed-water supply to one steam generator. The first stage represents an SBO without any auxiliary feedwater system actuation, and in the second stage, water injection to steam generator 2 permits the cooldown of ATLAS facility.

Once the test initial conditions are reached, a trip signal is induced to stop the turbine, the primary system reactor coolant pumps (RCP) and the feedwater pumps. Simultaneously, the main steam isolation valves (MSIV) close and the core power starts decaying.

When stopping water supply, secondary system pressure increases and reaches the main steam safety valves (MSSV) opening set value, through which inventory is discharged to a condensation tank. As the steam generators drain, heat transfer through U-tubes degrades and primary system pressure and temperature 
increase. Likewise, primary system inventory is discharged through a pilot-operated safety relieve valve (POSRV) placed at the safety depressurization line.

Since heat losses through the pressurizer need to be compensated during prolonged transients, a proportional heater operates until the first opening of the POSRV, supplying $16.36 \mathrm{~kW}$ at constant power.

The second phase of the test starts with the auxiliary feedwater system activation, when the peak-clad temperature in the core reaches $450{ }^{\circ} \mathrm{C}$. Recovering the feedwater supply through the downcomer nozzle of the steam generator 2 , a flow rate of about $0.981 \mathrm{~kg} / \mathrm{s}$ is provided periodically, to keep the water level in a range between $25 \%$ and $40 \%$ in the steam generator 2 .

\section{RESULTS AND DISCUSSIONS}

\subsection{Steady-state conditions}

The initial tests conditions were established through SBO simulations in an APR1400. From MARS-KS code calculations, the initial and boundary test conditions were determined by applying ATLAS design scaling ratios [25].

The core power was calculated to be $1.642 \mathrm{MW}$ as an initial condition, and to follow 1.2 times the ANS73 curve [26] in order to simulate the decay heat power in the fuel elements.

Table 4 summarizes the relative errors (\%) obtained in measured values at ATLAS facility and with TRACE code respect to the test target values. It can be seen that all errors in the steady-state simulation are less than $5 \%$.

\begin{tabular}{|l|c|c|}
\hline \multicolumn{1}{|c|}{ Design parameters } & $\begin{array}{c}\text { Measured relative } \\
\text { error [15] }\end{array}$ & $\begin{array}{c}\text { TRACE5 relative } \\
\text { error }\end{array}$ \\
\hline Pressurizer pressure & 0 & 0 \\
\hline Core inlet temperature & 0 & 0.6 \\
\hline Core outlet temperature & 0.6 & 0 \\
\hline Cold leg flow & 0.5 & 1 \\
\hline Steam flow rate & 7 & 4 \\
\hline Feed water temperature & 0 & 0 \\
\hline Steam pressure & 0 & 0 \\
\hline Secondary side level & 0.4 & 3.4 \\
\hline
\end{tabular}

Table 4: Steady-state conditions.

\subsection{Transient results}

The results of the most relevant thermal-hydraulic variables in the tests A1.1 simulation are discussed in this section. These values are compared to the experimental series provided by KAERI. Table 5 summarizes the sequence of the main events observed during the experiment and their timing with TRACE5.

\begin{tabular}{|l|c|c|}
\hline \multicolumn{1}{|c|}{ Event } & Experiment $[\mathrm{s}]$ & Simulation [s] \\
\hline SBO start & 303 & 300 \\
\hline MSSV first opening & 315 & 312 \\
\hline SG dry out & 5893 & 5856 \\
\hline $1^{\text {st }}$ POSRV opening & 6751 & 6015 \\
\hline Pressurizer full & 8605 & 8061 \\
\hline RPV saturation & 8188 & 8222 \\
\hline AFW supply & 11398 & 11346 \\
\hline End of test & 15000 & 15000 \\
\hline
\end{tabular}

Table 5: Sequence of A1.1 events. 
In accordance with these events, the transient has been divided in five phases (I-V) to identify the main thermal-hydraulic phenomena.

\begin{tabular}{|c|c|c|c|c|}
\hline \multicolumn{3}{|c|}{$5893 \mathrm{~s}$} & \multicolumn{2}{|c|}{$11398 \mathrm{~s}$} \\
\hline I & II & III & IV & V \\
\hline Steady-state & Core heat decay & Single phase NC & $\begin{array}{l}\text { Prim. inventory } \\
\text { discharge }\end{array}$ & NC reactivation \\
\hline $\begin{array}{l}\text { Single } \\
\text { phase NC }\end{array}$ & & $\begin{array}{l}\text { Prim. inventory } \\
\text { discharge }\end{array}$ & NC interruption & Countercurrent flow \\
\hline & Sec. inventory discharge & & & Filling of SG2 \\
\hline & Primary system pressurization & & & Core cooling \\
\hline
\end{tabular}

When all active components are tripped at the beginning of the SBO, decay heat is transferred to the secondary system by natural circulation because steam generators temperature is lower than primary system coolant temperature. As secondary inventory boils, pressure increases and causes MSSVs to open and close cyclically and coolant to be discharged. Experimental discharged inventory through MSSVs and the steam generators dry out time at $5900 \mathrm{~s}$ are reproduced accurately, as shown in Figure 5. Since this moment, no more vapor is evacuated through the MSSVs although the heat transfer from the primary system is high. This event has been used as a reference point to normalize Figure 5, and the value 1 is assigned to the discharged inventory accumulated until then. From the results of this Figure 5 it is concluded that both the secondary inventory and the heat transfer from the U-tubes have been properly modeled.

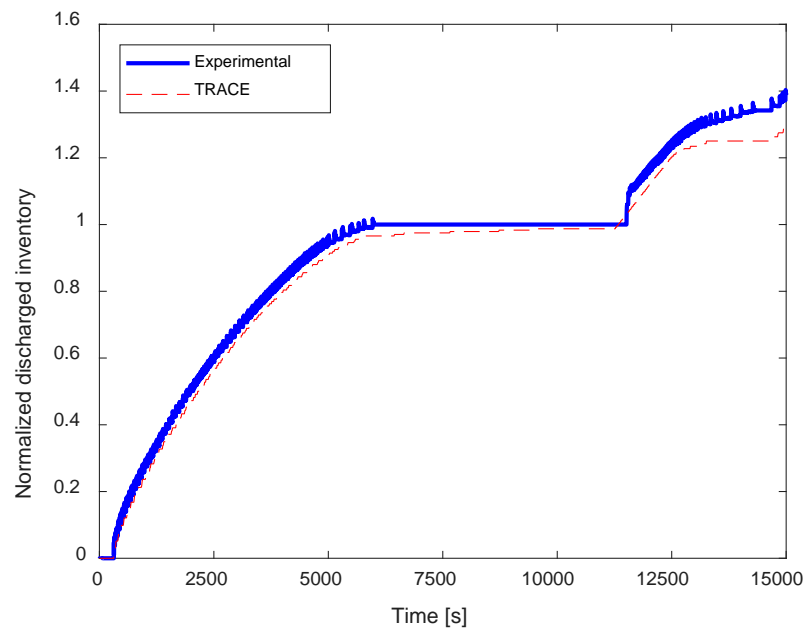

Figure 5: Total inventory discharged through MSSVs.

During steam generators dry out, the pressurizer water level decreases (Figure 6) while heat transfer through U-tube bundles is effective, and primary system pressure increases progressively (Figure 7). After steam generators boil off, heat transfer from primary to secondary system degrades and collapsed water level in the pressurizer changes its trend and increases sharply (5000 s to $7500 \mathrm{~s}$ ). As POSRV set point is reached, coolant is discharged through cyclic openings. 


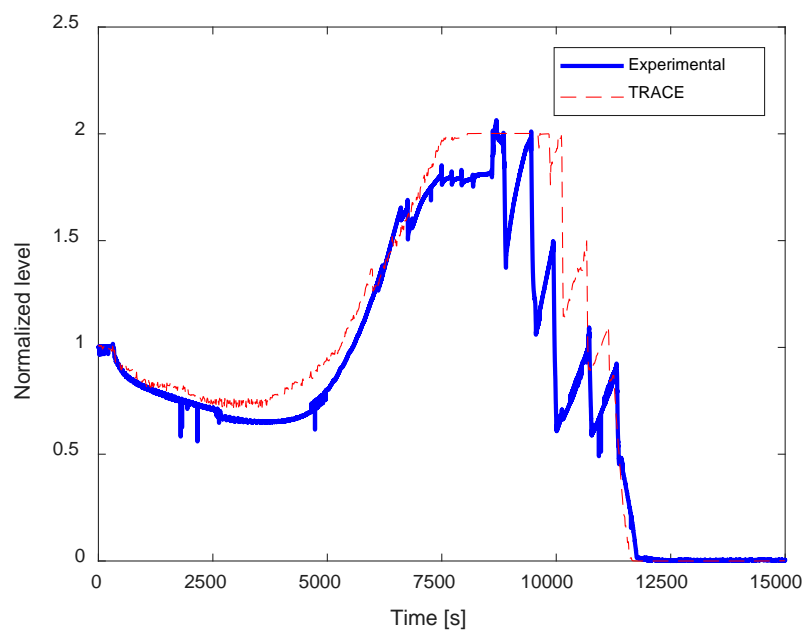

Figure 6: Collapsed water level in the pressurizer.

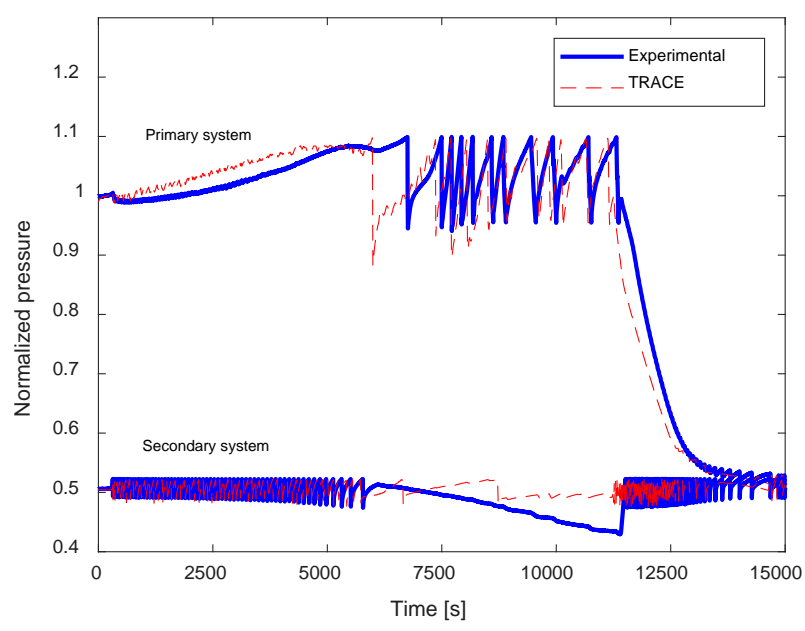

Figure 7: Primary and secondary system pressures.

Although the trend of the parameters measured in the pressurizer is well preserved, discrepancies between experimental and simulation data in primary system pressure appear (Figure 7), finding the first POSRV opening advanced $736 \mathrm{~s}$ respect to the experiment. It is also worth noting that once the steam generators become empty, the experimental pressure in these devices decreases while their safety valves remain closed, which is attributed to unexpected leakages in the MSSVs [33]. Once the auxiliary feedwater is supplied to the steam generator 2 (11398 s), experimental secondary pressure increases until the valves set point. However, in the steam generator 1, the leaks continue until the end of the transient. This involves lower temperature and pressure conditions in its riser.

As shown in Figure 8 and Figure 9, at the beginning of the experiment the hot legs flow decreases just as core decay heat curve does, and the natural circulation continues during the steam generators dry out phase. This phenomenon is held for some POSRV apertures, while the vessel is full. Once the pressurizer is completely filled up, the vessel takes its function when the upper plenum and upper head liquid become to saturated conditions. Meanwhile, consecutive larger discharges through POSRV drain the primary system and natural circulation flow terminates.

Since the auxiliary feedwater injection, experimental mass flow through the hot legs shows different trends. In loop 1, the upward gas flow in the U-tubes condenses due to the low temperature in the riser and returns 
along the hot leg 1. Despite reflux condensation is considered as one of the possible core cooling methods under accidental conditions [34], the small countercurrent flow generated is not the SBO mitigating cause. On the contrary, the auxiliary feedwater injection enhances the flow mass in the loop 2 . When the heat removal capacity of the steam generator 2 is recovered, a natural circulation flow along the loop 2 is reestablished.

TRACE5 results follow the experimental behavior over most of the transient. Single phase natural circulation flow is exactly reproduced during the steam generators emptying and the first POSRV openings. Then, the experimental and simulation NC interruption is simultaneous. In Figure 9, the cooling effect of the auxiliary feedwater drags a gas-liquid mixture through the loop 2. A value of 0.45 in the void fraction and the low flow velocity disclose a stratified flow pattern, which is the predictable one according to the experimental phenomena.
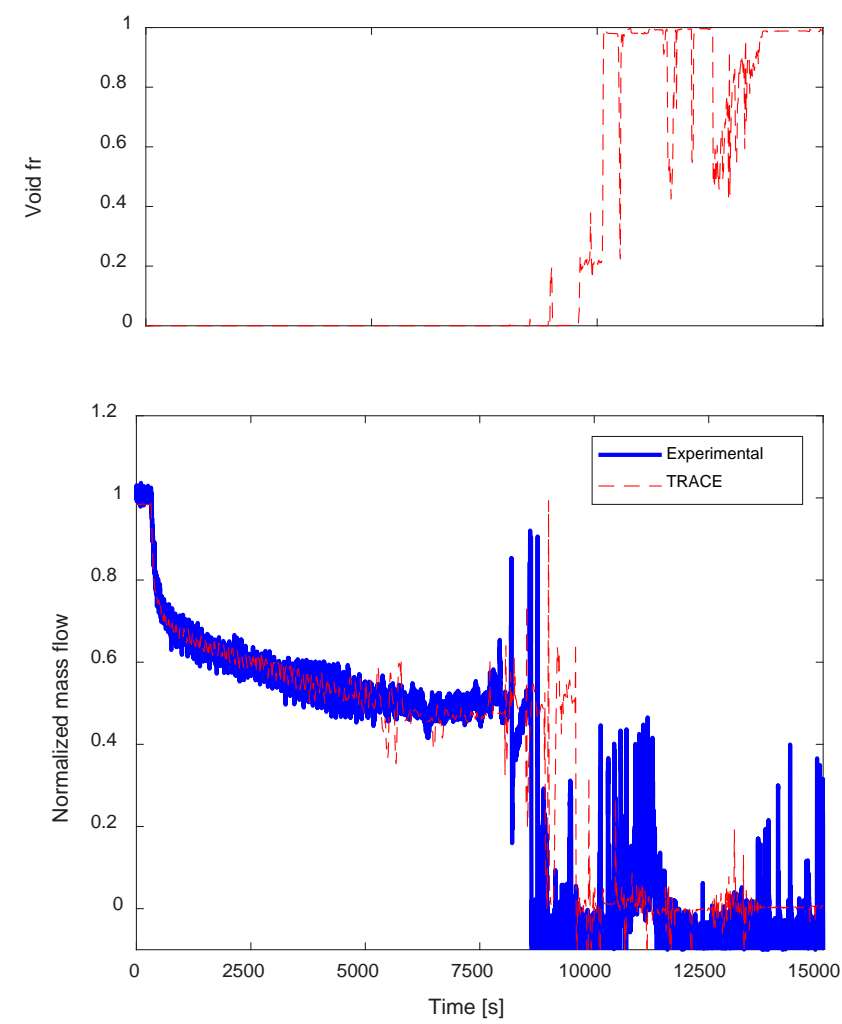

Figure 8: Mass flow and void fraction in hot leg 1. 

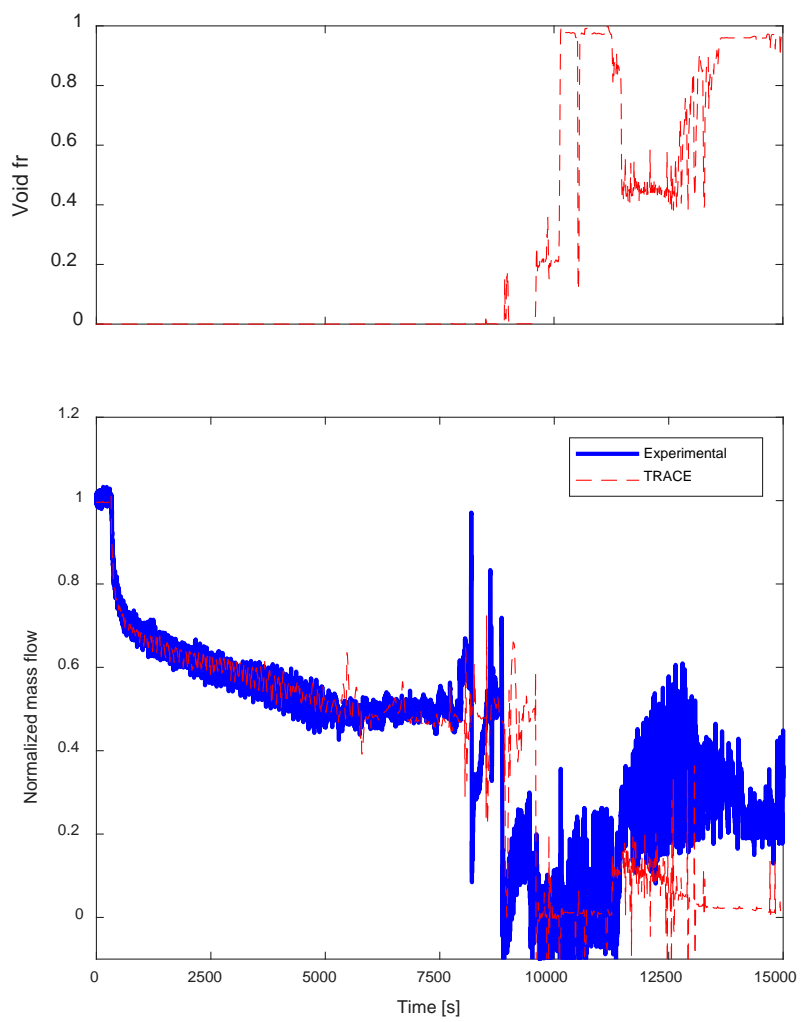

Figure 9: Mass flow and void fraction in hot leg 2.

The collapsed water level in the vessel is presented in Figure 10. The faster coolant loss decreases drastically the liquid level, leading to the core uncovering, and interrupts natural circulation phenomena. By comparing Figure10 with the flow charts (Figure 8 and Figure 9), the simultaneity of the flows interruption and the emptying of the vessel at $8600 \mathrm{~s}$ is appreciated.

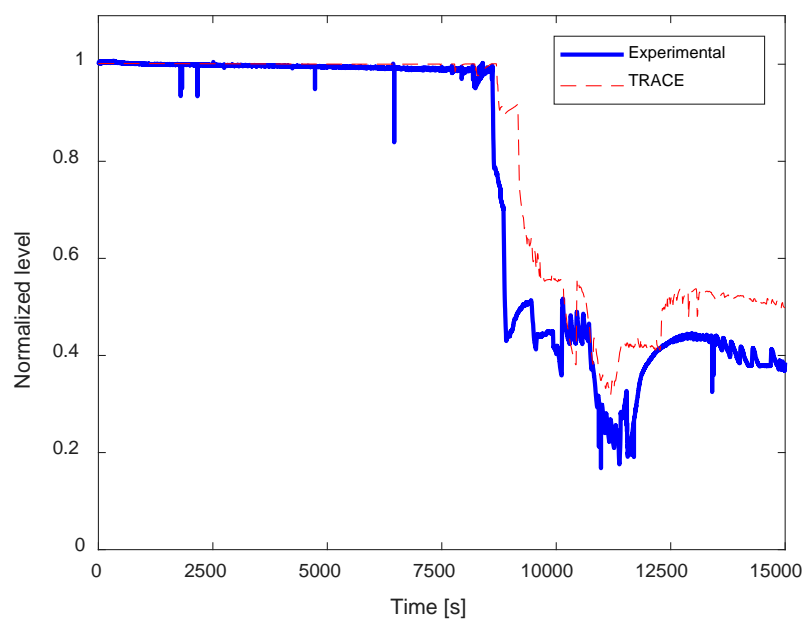

Figure 10: Collapsed water level in the RPV. 
Figure 11 presents the simulation results of the void fraction in the downward part of the U-tube bundle 2. The measurement at different locations shows the condensation mechanism which is responsible of the core cooling. Since the water level falling in the primary system, the upward side of the tubes remains under saturated conditions. By contrast, an amount of water appears in the downward side. The water injection cools the wall of the tubes near the economizer below the saturation temperature. As a consequence, a liquid film starts forming and flows downward under the influence of gravity. In this process, the thickness of the film increases as the liquid flows and it is reflected in the different void fraction measurements.

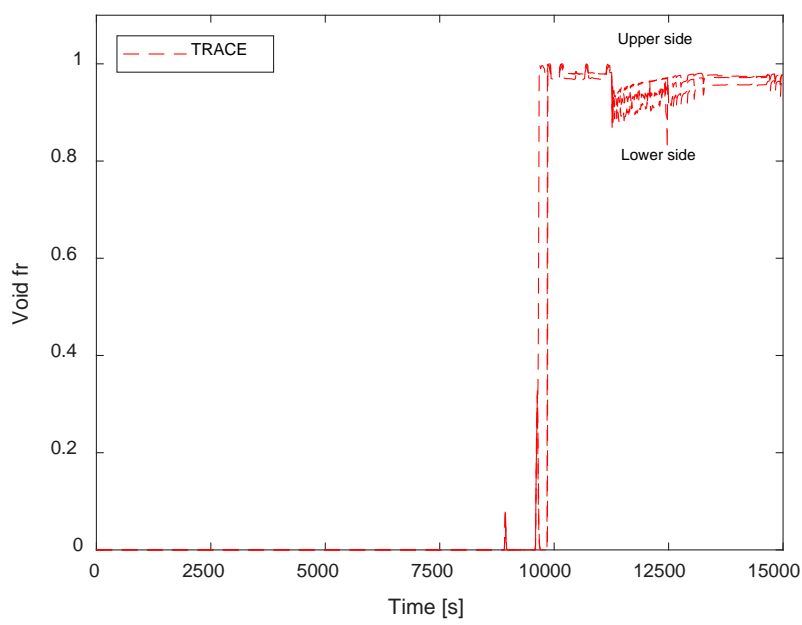

Figure 11: Void fraction in U-tube bundle 2.

Figure 12 shows the water temperature measured at the core inlet and outlet. As both temperatures are almost the same in the simulation and the experimental data, it means that the net power supplied (core power minus heat losses) and the heat transfer through the U-tubes are also consistent.

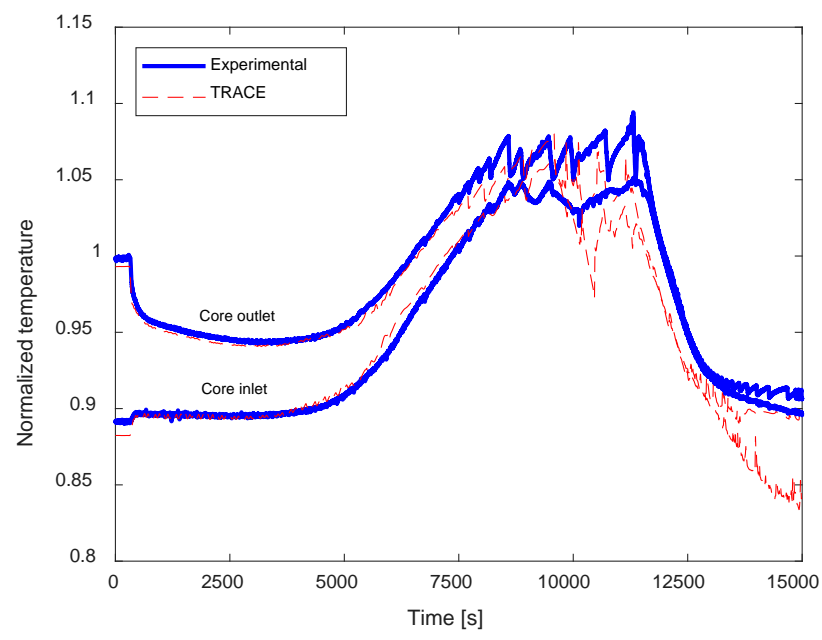

Figure 12: Core inlet and outlet temperature.

Figure 13 shows the accumulated discharged inventory through the POSRV. The steps in the graph correspond to the cyclic openings and closures of the valve, which are simulated correctly in time. However, a discrepancy in the final discharged inventory is detected and it affects the fluid conditions in the primary system at the end of the transient. The final collapsed water level in the vessel is overestimated in the simulation, and as a result, the loop seal clearing is not successfully reproduced. This is reflected in the discrepancies found in the hot leg 2 mass flow rate (Fig9). In the experimental data, once the mitigating 
action is taken (11346 s), the mass flow along the hot leg 2 reactivates, while this phenomenon is not properly reproduced.

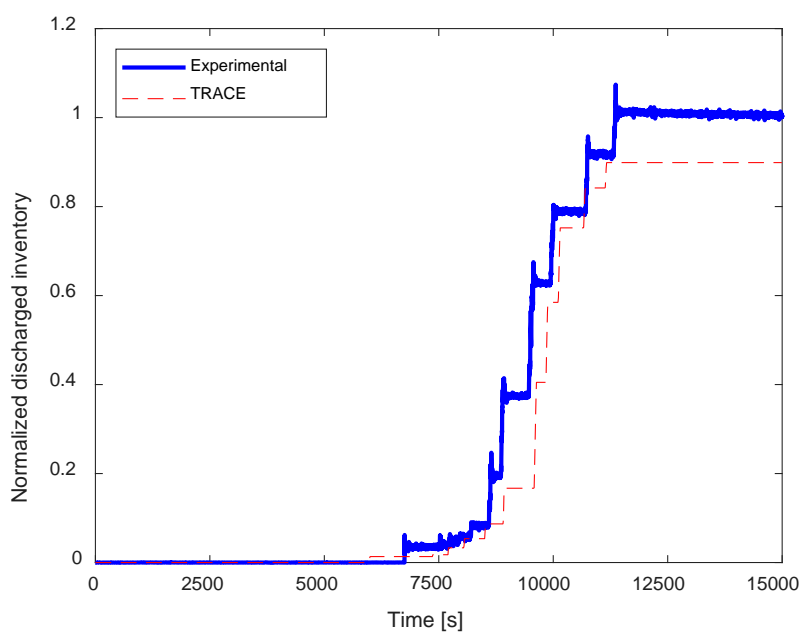

Figure 13: Total inventory discharged through POSRV.

Nevertheless, it is important to consider the two-phase flow measurement distortion, as the flow meters can measure within a $\pm 15 \%$ uncertainty error [26]. This fact will be taken into account when continuing the investigation on the discrepancies mentioned. Moreover, the end of natural circulation may be appreciated in Figure 14. In this ATLAS scheme, a rapid transition of the fluid condition takes place along the U-tube bundles as a consequence of the heat sink elimination.

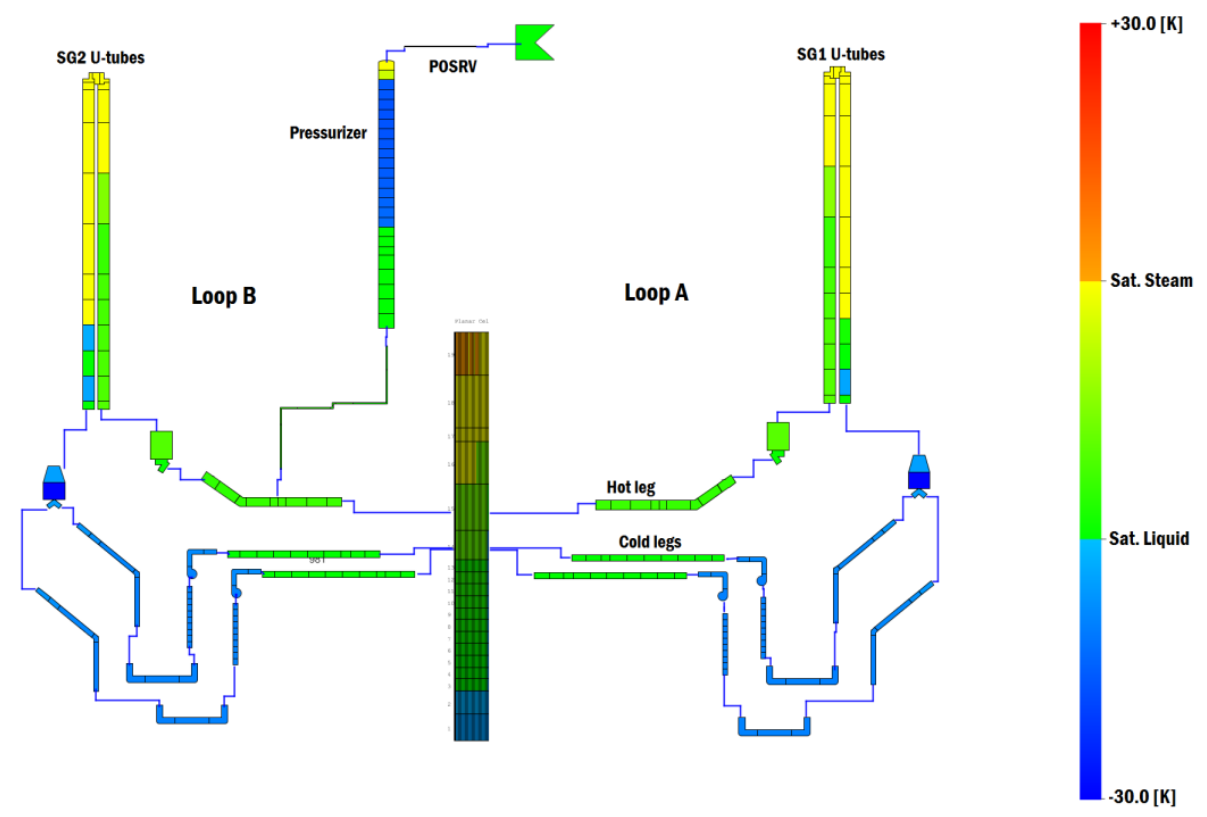

Figure 14: Fluid condition scheme. Natural circulation flow ending.

The peak-clad temperature (PCT) selected to put into operation the auxiliary feedwater system is $450{ }^{\circ} \mathrm{C}$, as mentioned in the test description. According to this variable, the auxiliary feedwater supply proves to be a very effective measure to stabilize the PCT due to the recovery of the core level. The precise simulation of the PCT shown in Figure 15 is remarkable. The excursion occurs at the same time in both the simulation 
and the experiment and reaches the same maximum value. These results prove the capacity of the model for the prediction of accidents.

Moreover, Figure 15 shows some the heat losses modeling effects in the transient results. The experimental and simulated PCT are drawn together with the results of simulating the Test A1.1 with an adiabatic model. During the first phase of the transient, the lack of heat losses increases the net power transferred to the steam generators and this shortens their emptying phase. Furthermore, since the heat transfer to the secondary system become negligible, the core heats more sharply and the POSRV opening succeed more often. The PCT excursion occurs in both cases when the discharge of water uncovers the core, and in the adiabatic case, it is advanced from 11346 s to 8266 s. In Figure 15, the PCT reaches the same maximum value, because it is controlled by the auxiliary feedwater injection.

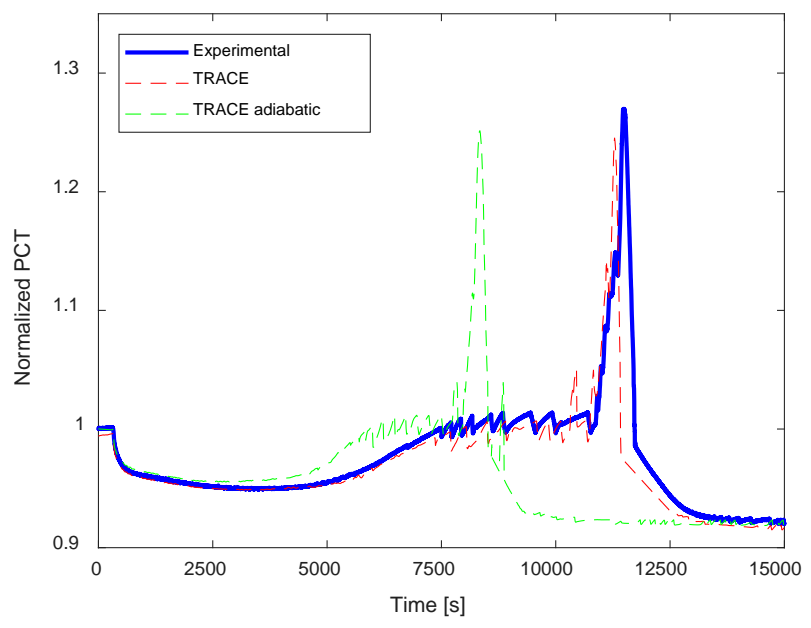

Figure 15: Peak-clad temperature.

\section{CONCLUSIONS}

This work presents a study on natural circulation phenomena found during a station blackout scenario with asymmetric and delayed feed-water supply to one steam generator. To that end, experimental results of the test A1.1 belonging to OECD-ATLAS project are analyzed and simulated with TRACE5 code.

Comparison between experimental and calculated data shows TRACE5 code capability to reproduce station blackout type transients, providing that a proper model is available. Likewise, it is shown the need to study all the thermal-hydraulic phenomena identified during the test, independently. To develop the model, the attention is focused on the heat structures sizing and the convective heat transfer coefficients estimation, because heat losses through the walls clearly affect natural circulation phenomena. To this end, the modeling technique using constant heat transfer coefficients is combined with a study of the model response under different HTC.

In a test facility, heat losses may be measured through experiments planned for this purpose, however, this parameter cannot be properly controlled in order to study their importance. For this reason, to model certain scenarios, a thermal-hydraulic code which allows analyzing the contribution of heat losses to the natural circulation capacity is necessary. A net power - mass flow correlation under steady-state natural circulation conditions is developed making use of TRACE5 code. The comparison of such correlation with other correlations obtained experimentally shows a good agreement, and therefore the suitability of thermalhydraulic codes for thermal studies. The results of heat losses analysis have been used to define the boundary conditions in the simulation of the A1.1 experimental test by TRACE5 code. The comparison between experimental results and TRACE predictions shows a good agreement as far as pressures and temperatures of the primary and secondary coolant, peak-clad temperature, pressurizer level and natural 
circulation flow rates; on the other hand, slight discrepancies are found in the final inventory of primary coolant and collapsed level in the RPV.

Taking into account the importance of thermal processes on natural circulation during the SBO accident, the results prove the adequacy of the methodology used to model heat losses.

\section{Acknowledgements}

The authors are grateful to the Management Board of the OECD-ATLAS Project for their consent to this publication, and thank the Spanish Nuclear Regulatory Body (CSN) for the technical and financial support under the agreement STN/4524/2015/640. They also thank Ronald Harrington, from USNRC, for sharing the preliminary TRACE model used in this work.

\section{REFERENCES}

[1] Yeon-Sik Kim, First ATLAS domestic standard problem (DSP-01) for the code assessment, Nucl. Eng. Tech., 43 (2011) 25-44.

[2] IAEA, Natural Circulation Phenomena and Modelling for Advanced Water Cooled Reactors. IAEATECDOC-1677 (2012).

[3] IAEA, Natural circulation in water cooled nuclear power plants. IAEA-TECDOC-1474 (2005).

[4] S. Wongwises, Two-phase counter current flow in a model of a pressurized water reactor hot leg, Nucl. Eng. Des. 166 (1996) 121-133.

[5] H. T. Kim, H. C. No, Assessment of RELAP5/MOD3.2.2 $\gamma$ against flooding database in horizontal-toinclined pipes, Ann. Nucl. Energy 29 (2002) 835-850.

[6] IAEA, Natural circulation data and methods for advanced water cooled nuclear power plant designs. IAEA-TECDOC-1281 (2002).

[7] J. Zou, Q. Li, L. L. Tong, X. W. Cao, Assessment of passive residual heat removal system cooling capacity, Prog. Nucl. Energ. 70 (2014) 159-166.

[8] T. Yonomoto, Y. Kukita, R. R. Schultz, Heat Transfer Analysis of the Passive Residual Heat Removal System in ROSA/AP600 Experiments, Nucl. Technol. 124 (1998) 18-30.

[9] H. Park, et al., Experiments on the performance sensitivity of the passive residual heat removal system of an advanced integral type reactor, Nucl. Eng. Tech., 41 (2009) 53-62.

[10] J. Wu, Q.Bi, C.Zhou, Experimental study on circulation characteristics of secondary passive heat removal system for Chinese pressurized water reactor, Applied Thermal Engineering, 77 (2015) 106-112.

[11] S. Kim, et al., An experimental study on the validation of cooling capability for the Passive Auxiliary Feedwater System (PAFS) condensation heat exchanger, Nucl. Eng. Des. 260 (2013) 54-63.

[12] V.Vinod, et al., Experimental evaluation of safety grade decay heat removal in prototype fast breeder reactor, Nucl. Eng. Des. 265 (2013) 1057-1065.

[13] M. Caramello, et al., Thermal hydraulic analysis of a passively controlled DHR system, Prog. Nucl. Energ. 99 (2017) 127-139.

[14] K. Kang, Development of a phenomena identification ranking table for simulating a station blackout transient of a pressurized water reactor with a thermal-hydraulic integral effect test facility, Ann. Nucl. Energy 75 (2015) 72-78. 
[15] M. Ishii, I. Kataoka, Scaling laws for thermal-hydraulic system under single phase and two-phase natural circulation, Nucl. Eng. Des. 81 (3) (1984) 411-425.

[16] Y.A. Zvirin, A review of natural circulation loops in pressurized water reactors and other systems, Nucl. Eng. Des. 67 (2) (1981) 203-225.

[17] Jang Byeong-ll, Kim MooHwan, Jeun Gyoodong, Experimental and computational investigation of a natural circulation system in Regional Energy Reactor-10MWth, Nucl. Eng. Des. 241 (2011) 2214-2223.

[18] Z.M. Yang, et al., The solution type and experimental verification of steady-state flow rate of onedimension single-phase natural circulation loop, Chin. J. Nucl. Sci. Eng. 19 (3) (1999) 248-252.

[19] W. Lei, L. Yang, J. Hai-jun, W. Jun, Innovative flow-resistance performance in the single-phase natural circulation loop and relevant experiment verification, Int. J. Heat Mass Transfer 107 (2017) 66-73.

[20] S.C. Tan, G.H. Sun, P.Z. Gao, Experimental and theoretical study on single-phase natural circulation flow and heat transfer under rolling motion condition, Appl. Therm. Eng. 29 (2009) 3160-3168.

[21] J. Y. Kudariyawar, et al., Computational and experimental investigation of steady state and transient characteristics of molten salt natural circulation loop, Appl. Therm. Eng. 99 (2016) 560-571.

[22] A. K. Srivastava, et al., Experimental and theoretical studies on the natural circulation behavior of molten salt loop, Appl. Therm. Eng. 98 (2016) 513-521.

[23] N. Lamaison, C. L. Ong, J. B. Marcinichen, J. R. Thome, Two-phase mini-thermosyphon electronics cooling: Dynamic modeling, experimental validation and application to 2U servers, Appl. Therm. Eng. 110 (2017) 481-494.

[24] KAERI, Scaling Analysis Report of the ATLAS Facility, KAERI/TR-5465/2014 (2014).

[25] K. Y. Choi, et al., Simulation Capability of the ATLAS Facility for Major Design-Basis Accidents, Nucl. Technol. 156 (3) (2006) 256-269.

[26] OECD-ATLAS. Test Report for OECD-ATLAS A1.1 Test, OECD-ATLAS-TR-01 (2015).

[27] USNRC. TRACE V5.0 USER'S MANUAL Volume 2: Modeling Guidelines (2007).

[28] T. Cong, Study on secondary side flow of steam generator with coupled heat transfer from primary to secondary side, Appl. Therm. Eng. 61 (2013) 519-530.

[29] USNRC. TRACE V5.0 THEORY MANUAL (2011).

[30] K.G. Condie, et al., Evaluation of integral continuing experimental capability (CEC) concepts for light water reactor research - PWR scaling concepts, NUREG/CR-4824, EG\&G 2494 (1987).

[31] KAERI, ATLAS Facility and Instrumentation Description Report, KAERI/TR-3779/2009 (2009).

[32] S. Kakaç, Y. Yener, Convective heat transfer, CRC Press (1995) 18.

[33] Y. S. Kim, Analysis of a station blackout scenario with an ATLAS test, Nucl. Eng. Tech. 45 (2013) $179-190$

[34] Deendarlianto, et al., Gas-liquid countercurrent two-phase flow in a PWR hot leg: A comprehensive research review, Nucl. Eng. Des. 243 (2012) 214-233. 